\title{
Seroprevalence of Toxoplasma gondii infection and associated risk factors in Huicholes in Mexico
}

\author{
Cosme Alvarado-Esquivel ${ }^{1 *}$, Sandy Janet Pacheco-Vega ${ }^{1}$, Jesús Hernández-Tinoco², \\ Luis Francisco Sánchez-Anguiano², Luis Omar Berumen-Segovia ${ }^{2}$, Francisco Javier Imard Rodríguez-Acevedo ${ }^{3}$, \\ Isabel Beristain-García ${ }^{4}$, Elizabeth Rábago-Sánchez ${ }^{1}$, Oliver Liesenfeld ${ }^{5,6}$, Federico Campillo-Ruiz ${ }^{3}$ \\ and Oscar Alberto Güereca-García ${ }^{4}$
}

\begin{abstract}
Background: Very little is known about the seroepidemiology of Toxoplasma gondii infection in ethnic groups in Mexico. Huicholes are an indigenous ethnic group living in a remote mountainous region in Mexico. We sought to determine the prevalence of anti-Toxoplasma IgG and IgM antibodies in Huicholes; and to determine the association of Toxoplasma seropositivity with socio-demographic, behavioral, and clinical characteristics of Huicholes.

Methods: We performed a cross sectional survey in Huicholes from September 2013 to January 2014. A convenience sampling method was used. We investigated the prevalence of anti-Toxoplasma IgG and IgM antibodies in 214 Huicholes using enzyme-linked immunoassays. A standardized questionnaire was used to obtain the characteristics of the Huicholes. Bivariate and multivariate analyses were used to assess the association of Toxoplasma exposure and Huicholes' characteristics.

Results: Of the 214 Huicholes studied (mean age: $37.98 \pm 15.80$ years), 71 (33.2\%) were positive for anti-T. gondii IgG antibodies and 47 (66.2\%) of them were also positive for anti-T. gondii IgM antibodies. Seroprevalence of T. gondii infection did not vary with age, sex, or occupation. However, seroprevalence of anti-T. gondii IgM antibodies was significantly higher in female than in male Huicholes. Multivariate analysis of socio-demographic and behavioral characteristics showed that $T$. gondii exposure was associated with consumption of turkey meat $(\mathrm{OR}=2.28 ; 95 \% \mathrm{Cl}$ : 1.16-4.46; $P=0.01$ ). In addition, seroprevalence of $T$. gondii infection was significantly higher in Huicholes suffering from dizziness and memory impairment than those without such clinical characteristics.
\end{abstract}

Conclusions: Our results demonstrate serological evidence of T. gondii exposure among Huicholes which may be impacting their health. Results of this first study of $T$. gondii infection in Huicholes may be useful for the design of optimal preventive measures against infection with $T$. gondii.

Keywords: Toxoplasma gondii, Seroprevalence, Huicholes, Cross-sectional study

\section{Background}

Infections with the parasite Toxoplasma gondii (T. gondii) occur worldwide [1] and affect about one third of humanity [2]. Although most infections with T. gondii are asymptomatic, some infected individuals may suffer from symptomatic pathological changes in the lymph nodes, eyes, and central nervous system [3]. In addition, pregnant women

\footnotetext{
* Correspondence: alvaradocosme@yahoo.com

'Biomedical Research Laboratory, Faculty of Medicine and Nutrition, Juárez University of Durango State, Avenida Universidad S/N, 34000 Durango, Dgo, Mexico

Full list of author information is available at the end of the article
}

with primary infection with $T$. gondii may transmit the infection to the fetus leading to congenital disease [4]. Immunocompromised individuals infected with T. gondii may develop a life-threatening disease [5]. Ingestion of food or water contaminated with oocysts shed by cats $[3,6]$ and eating undercooked or raw meat containing tissue cysts $[3,7,8]$ are important routes of $T$. gondii transmission.

Very little is known about the epidemiology of $T$. gondii infection in ethnic groups in Mexico. We have previously studied the seroepidemiology of $T$. gondii infection in Mennonites [9] and Tepehuanos [10] in Durango, Mexico. To the best of our knowledge, there is not any report

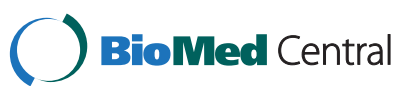


about the epidemiology of $T$. gondii infection in Huicholes (an indigenous ethnic group living in a remote mountainous region (Sierra Madre Occidental) in the western central Mexican states of Nayarit, Durango, Jalisco and Zacatecas. Life style in Huicholes differs from that in other rural population groups in Durango; they live in marked poverty with very poor housing and sanitary conditions. They have limited access to health care services, and Hospitals in their region do not have a number of laboratory tests for diagnosis of infectious diseases i.e., infection with $T$. gondii. It is important to study the epidemiology of $T$. gondii infection in Huicholes because they live in a climatic scenario that may favor T. gondii infection. Huicholes live in a warmer and more humid area than other population groups in the region. Environmental factors may contribute to a higher seroprevalence of $T$. gondii infection $[1,11]$. In general, the seroprevalence of $T$. gondii infection is higher in humid climates than in dry climates; and this is the case in humans [12-14] and animals [15-17]. Furthermore, Huicholes eat meat from wild animals that may be infected with $T$. gondii. Therefore, we sought to determine the seroprevalence of T. gondii exposure in Huicholes and the association of Toxoplasma seropositivity with socio-demographic, behavioral, and clinical characteristics of Huicholes.

\section{Methods}

\section{Study design and study population}

We performed a cross sectional survey in Huicholes in Mexico from September 2013 to January 2014. Huicholes were sampled in the locality of Huazamota in the municipality of El Mezquital in Durango State, Mexico. Huazamota $\left(23^{\circ} 28^{\prime} \mathrm{N} 104^{\circ} 24^{\prime} \mathrm{W}\right)$ has an altitude of 600 meters above sea level, a warm-sub-humid climate, and a mean annual temperature of $19.2^{\circ} \mathrm{C}$. The south region of El Mezquital municipality has a mean annual rainfall varying from 800 to $1000 \mathrm{~mm}$. Other ethnic groups live in the mountainous region including Mexicaneros and Tepehuanos. Inclusion criteria for the study subjects were: 1) Huichol ethnicity (people who speak the Huichol language and identify themselves as Huicholes); 2) aged 14 years and older; and 3) that voluntarily accepted to participate.

\section{Sample size and sampling method}

For calculation of the sample size, we used a reference seroprevalence of $22.4 \%$ [10] as expected frequency of the factor under study, 7,000 as the size of population from which the sample was selected, $16.9 \%$ as the least acceptable result, and a confidence level of $95 \%$. The result of the calculation was 214 subjects. A convenience sampling method was used. Specifically, the authors approached Huicholes leaders for permission and support; each leader communicated and invited all people under his command; those who accepted the invitation gathered in a specific area to provide socio-demographic data and blood sample; 214 people who met the inclusion criteria were enrolled.

\section{Socio-demographic, clinical, and behavioral data}

We used a standardized questionnaire to obtain the sociodemographic, clinical and behavioral characteristics of the Huicholes. Socio-demographic items were age, sex, birth place, residence, educational level, occupation, and socioeconomic status. Clinical data included the presence of underlying diseases, presence or history of lymphadenopathy, frequent presence of headache, dizziness, impairments of memory, reflexes, hearing, and vision, and a history of surgery, blood transfusion or transplants. Clinical data including impairments was self-reported. Huicholes were considered "ill" when they suffered from any disease either acute or chronic affecting any organ or system i.e. digestive, respiratory, circulatory, endocrine, or nervous, and included any psychiatric, rheumatic, hematological or nutritional disorder and any type of morbidity. In Huichol women, obstetric data were also obtained. Behavioral items included animal contacts, contact with cat excrement, foreign travel, meat consumption (pork, beef, goat, lamb, boar, chicken, turkey, pigeon, duck, rabbit, venison, squirrel, horse, opossum, or other), frequency of meat consumption, consumption of raw or undercooked meat, unpasteurized milk, dried or processed meat (ham, sausages or chorizo), consumption of unwashed raw vegetables, fruits, or untreated water, frequency of eating away from home (in restaurants or fast food outlets), contact with soil (gardening or agriculture), and type of flooring at home from all participants were obtained.

\section{Serological examination for $T$. gondii antibodies}

Serum samples were obtained from about $3 \mathrm{ml}$ of whole blood. Sera were kept frozen at $-20^{\circ} \mathrm{C}$ until analyzed. All sera were analyzed by qualitative and quantitative methods for anti-T. gondii IgG antibodies with a commercially available enzyme immunoassay "Toxoplasma IgG" (Diagnostic Automation Inc., Calabasas, CA, USA). Anti-T. gondii IgG antibody levels were expressed as International Units (IU)/ $\mathrm{ml}$, and a cut-off of $\geq 8 \mathrm{IU} / \mathrm{ml}$ was used for seropositivity. In addition, sera positive for T. gondii IgG were further analyzed for anti-T. gondii IgM antibodies by a commercially available enzyme immunoassay "Toxoplasma IgM" kit (Diagnostic Automation Inc., Calabasas, CA, USA). The cut-off for IgM seropositivity for each assay was obtained by multiplying the mean cut-off calibrator optical density by a correction factor $(f=0.35-0.40)$ printed on the label of calibrator. All assays were performed following the instructions of the manufacturer and included positive and negative controls in each run. A positive IgG test and a negative IgM test in a participant was interpreted as a latent infection. A positive IgG test and a positive IgM test in a participant was interpreted as probability of a recent or acute infection. 


\section{Statistical analysis}

We used the Epi Info version 3.5.4 and SPSS version 15.0 software for the statistical analysis. The Pearson's chisquare test and the Fisher exact test (when values were less than 5) were used for initial comparison of the frequencies among groups. Multivariate analysis was used to assess the association between the characteristics of the Huicholes and the seropositivity to $T$. gondii. Variables were included in the multivariate analysis if they had a $P$ value equal to or less than 0.15 in the bivariate analysis. Odds ratio (OR) and 95\% confidence interval (CI) were calculated by multivariate analysis using the Enter method. The Hosmer-Lemeshow goodness of fit test was used to assess the fitness of the regression model. A $P$ value $<0.05$ was considered statistically significant.

\section{Ethical aspects}

The purpose and procedures of the survey were explained to all Huicholes. This study was approved by the Ethical Committee of the General Hospital of the Secretary of Health in Durango City, Mexico. Participation in the study was voluntary and a written informed consent was obtained from all participants and from the next of kin of minor participants. All Huicholes were proficient in Spanish and understood explanations about the purpose and procedure of the survey as well as the informed consent provided by the interviewers. Results of the laboratory tests were sent to the Huicholes' nearest Hospital (Huazamota) where health care providers could inform participants about their results and provide them with medical care if needed.

\section{Results}

In total, we enrolled 214 Huicholes in the study including 86 (40.2\%) males and 128 (59.8\%) females. Most Huicholes were born in Durango; their mean age was $37.98 \pm 15.80$ years (range $14-82$ years). General sociodemographic characteristics of the 214 Huicholes studied are shown in Table 1.

Of the 214 Huicholes studied, 71 (33.2\%) were positive for anti-T. gondii IgG antibodies and 47 (66.2\%) of them had anti-T. gondii IgM antibodies. Of the 71 anti-T. gondii IgG positive participants, 26 (36.6\%) had IgG levels higher than $150 \mathrm{IU} / \mathrm{ml}, 1$ (1.4\%) between 100 to $150 \mathrm{IU} /$ $\mathrm{ml}$, and $44(62.0 \%)$ between 9 to $99 \mathrm{IU} / \mathrm{ml}$.

Seroprevalence of $T$. gondii infection did not vary significantly with age, sex, birthplace, residence, occupation or socioeconomic level of Huicholes (Table 1). In contrast, seroprevalence varied significantly with educational level; Huicholes with no education had the highest seroprevalence of $T$. gondii exposure (40.2\%). In the 71 Huicholes seropositive for anti- $T$. gondii IgG antibodies, the prevalence of anti-T. gondii IgM antibodies was significantly higher in female (33/42: 78.6\%) than in male (14/29:
Table 1 Socio-demographic characteristics of Huicholes and seroprevalence of $T$. gondii infection

\begin{tabular}{|c|c|c|c|c|}
\hline \multirow[t]{2}{*}{ Characteristic } & \multirow[t]{2}{*}{$\begin{array}{c}\text { No. of } \\
\text { subjects tested }\end{array}$} & \multicolumn{2}{|c|}{$\begin{array}{l}\text { Prevalence } \\
\text { of } T \text {. gondii } \\
\text { infection }\end{array}$} & \multirow[t]{2}{*}{$P$ value } \\
\hline & & No. & $\%$ & \\
\hline \multicolumn{5}{|l|}{ Age groups (years) } \\
\hline 30 or less & 80 & 21 & 26.3 & 0.09 \\
\hline $31-50$ & 90 & 30 & 33.3 & \\
\hline$>50$ & 44 & 20 & 45.5 & \\
\hline \multicolumn{5}{|l|}{ Sex } \\
\hline Male & 86 & 29 & 33.7 & 0.89 \\
\hline Female & 128 & 42 & 32.8 & \\
\hline \multicolumn{5}{|l|}{ Birth place } \\
\hline Durango state & 181 & 57 & 31.5 & 0.22 \\
\hline Other Mexican state & 33 & 14 & 42.4 & \\
\hline \multicolumn{5}{|l|}{ Residence } \\
\hline Durango state & 210 & 69 & 32.9 & 0.6 \\
\hline $\begin{array}{l}\text { Other Mexican State } \\
\text { or abroad }\end{array}$ & 4 & 2 & 50.0 & \\
\hline \multicolumn{5}{|l|}{ Educational level } \\
\hline No education & 87 & 35 & 40.2 & 0.02 \\
\hline $1-6$ years & 77 & 27 & 35.1 & \\
\hline$>6$ years & 50 & 9 & 18.0 & \\
\hline \multicolumn{5}{|l|}{ Occupation } \\
\hline Labourer $^{a}$ & 107 & 34 & 31.8 & 0.66 \\
\hline Non-labourer ${ }^{b}$ & 107 & 37 & 34.6 & \\
\hline \multicolumn{5}{|l|}{ Socio-economic level } \\
\hline Low & 201 & 69 & 34.3 & 0.16 \\
\hline Medium & 13 & 2 & 15.4 & \\
\hline
\end{tabular}

aLabourer: Agriculture, construction, business, livestock raising, factory worker, other. ${ }^{b}$ Non-labourer: student, housekeeping or none occupation.

48.3\%), Huicholes $(P=0.008)$. Prevalence of high $(>150 \mathrm{IU} /$ ml) IgG antibody levels was similar in female $(16 / 128$ : $12.5 \%)$ and male (10/86: $11.6 \%)$, Huicholes $(P=0.84)$.

Concerning clinical characteristics, seroprevalence of anti-T. gondii IgG was significantly higher in Huicholes suffering from dizziness and memory impairment than those without such clinical characteristics (Table 2). The frequency of $T$. gondii exposure in subjects with dizziness and memory impairment did not vary with age $(P=0.19$ and $P=0.48$, respectively). The frequencies of other clinical characteristics including the presence of underlying diseases; suffering from frequent headaches; presence or history of lymphadenopathy; reflexes, hearing and visual impairments; histories of surgery, blood transfusion, and transplant were similar among $T$. gondii positive and $T$. gondii negative individuals. Histories of miscarriage and stillbirth in women were not associated with T. gondii seropositivity. 
Table 2 Bivariate analysis of clinical data and infection with $T$. gondii in Huicholes

\begin{tabular}{lccc}
\hline Characteristic & $\begin{array}{c}\text { Subjects } \\
\text { tested* no. }\end{array}$ & $\begin{array}{c}\text { Prevalence } \\
\text { of } T \text {. gondii } \\
\text { infection }\end{array}$ & $P$ value \\
\cline { 2 - 3 } & No. $\%$ &
\end{tabular}

Clinical status

Healthy

III

Lymphadenopathy ever

Yes
No
Headache frequently
Yes
No

Memory impairment

$$
\text { Yes }
$$

$$
\text { No }
$$

Dizziness

Yes

No

Reflexes impairment

Yes

No

Hearing impairment

$$
\begin{aligned}
& \text { Yes } \\
& \text { No }
\end{aligned}
$$

Visual impairment

$$
\text { Yes }
$$

No

Surgery ever

Yes

No

Transplantation

Yes

No

Blood transfusion

$$
\text { Yes }
$$

No

Pregnancies

None

One to three

Four to six

More than six

Deliveries

Zero
171

41

$\begin{array}{lll}59 & 34.5 & 0.34 \\ 11 & 26.8 & \end{array}$

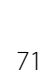

143

$$
28
$$

43

39.4

43

30.1

$\begin{array}{ll}64 & 35 \\ \end{array}$

Table 2 Bivariate analysis of clinical data and infection with $T$. gondii in Huicholes (Continued)

\begin{tabular}{lcccc}
\hline One to three & 44 & 12 & 27.3 & \\
Four to six & 44 & 16 & 36.4 & \\
Seven to nine & 19 & 9 & 47.4 & \\
$\quad$ Nine to twelve & 7 & 3 & 42.9 & \\
Cesarean sections & & & & \\
$\quad$ No & 115 & 37 & 32.2 & 0.64 \\
$\quad$ Yes & 13 & 5 & 38.5 & \\
Miscarriages & & & & \\
$\quad$ No & 97 & 32 & 33 & 0.51 \\
$\quad$ Yes & 25 & 10 & 40 & \\
Stillbirths & & & & \\
$\quad$ No & 115 & 37 & 32.2 & 0.22 \\
$\quad$ Yes & 7 & 4 & 57.1 & \\
*Subjects with available data. & & & &
\end{tabular}

*Subjects with available data.

With respect to behavioral characteristics, a number of variables showed $P$ values lower than 0.15 in the bivariate analysis including presence of dogs at home $(P=0.06)$, consumption of raw dried meat $(P=0.14)$, and consumption of meat from goat $(P=0.14)$, turkey $(P=0.002)$, and pigeon $(P=0.04)$. A selection of behavioral characteristics and their correlation with $T$. gondii exposure are shown in Table 3. Other behavioral characteristics of Huicholes including contact with cats, cleaning cat excrement, raising animals, traveling, consumption of meat other than goat, turkey and pigeon meat, frequency of meat consumption, degree of meat cooking, consumption of unpasteurized milk, processed meat, unwashed raw vegetables or fruits, untreated water, frequency of eating out of home, soil contact, and soil flooring at home showed $P$ values higher than 0.15 in the bivariate analysis. Further analysis by using logistic regression showed that $T$. gondii exposure was only associated with consumption of turkey meat $(\mathrm{OR}=2.28 ; 95 \% \mathrm{CI}: 1.16-4.46 ; P=0.01)$ (Table 4$)$. A $P=$ 0.35 was obtained in the Hosmer-Lemeshow test indicating an acceptable fit of our regression model.

In the 71 Huicholes with anti-T. gondii IgG antibodies, seroprevalence of anti-T. gondii IgM antibodies was higher $(P=0.006)$ in Huicholes who raised animals $(41 / 55$; $74.5 \%)$ than in those without such practice (6/16: 37.5\%), and in Huicholes with consumption of raw dried meat $(35 / 46 ; 76.1 \%)$ than in those without such eating habit $(11 / 24: 45.8 \%)(P=0.01)$.

\section{Discussion}

The present study was performed to investigate the seroepidemiology of $T$. gondii infection in Huicholes in Mexico. Results indicate that Huicholes have one of the highest seroprevalences of $T$. gondii infection reported in the region. The seroprevalence found in Huicholes (33.2\%) is 
Table 3 Bivariate analysis of selected putative risk factors for infection with $T$. gondii in Huicholes

\begin{tabular}{lcc}
\hline Characteristic & $\begin{array}{c}\text { Subjects } \\
\text { tested }{ }^{*} \text { no. }\end{array}$ & $\begin{array}{c}\text { Prevalence } \\
\text { of } T \text {. gondii } \\
\text { infection }\end{array}$ \\
\cline { 2 - 2 } & No. $\%$
\end{tabular}

\begin{tabular}{|c|c|c|c|c|}
\hline \multicolumn{5}{|l|}{ Cats at home } \\
\hline Yes & 93 & 33 & 35.5 & \multirow[t]{2}{*}{0.53} \\
\hline No & 121 & 38 & 31.4 & \\
\hline \multicolumn{5}{|l|}{ Dogs at home } \\
\hline Yes & 165 & 60 & 36.4 & \multirow[t]{2}{*}{0.06} \\
\hline No & 49 & 11 & 22.5 & \\
\hline \multicolumn{5}{|c|}{ Goat meat consumption } \\
\hline Yes & 193 & 67 & 34.7 & \multirow[t]{2}{*}{0.14} \\
\hline No & 21 & 4 & 19 & \\
\hline \multicolumn{5}{|c|}{ Chicken meat consumption } \\
\hline Yes & 209 & 71 & 34 & \multirow[t]{2}{*}{0.17} \\
\hline No & 5 & 0 & 0 & \\
\hline \multicolumn{5}{|c|}{ Turkey meat consumption } \\
\hline Yes & 106 & 46 & 43.4 & \multirow[t]{2}{*}{0.002} \\
\hline No & 108 & 25 & 23.1 & \\
\hline \multicolumn{5}{|c|}{ Pigeon meat consumption } \\
\hline Yes & 176 & 63 & 35.8 & \multirow[t]{2}{*}{0.04} \\
\hline No & 37 & 7 & 18.9 & \\
\hline \multicolumn{5}{|l|}{ Venison consumption } \\
\hline Yes & 203 & 69 & 34 & \multirow[t]{2}{*}{0.34} \\
\hline No & 11 & 2 & 18.2 & \\
\hline \multicolumn{5}{|c|}{ Squirrel meat consumption } \\
\hline Yes & 63 & 25 & 39.7 & \multirow[t]{2}{*}{0.19} \\
\hline No & 151 & 46 & 30.5 & \\
\hline \multicolumn{5}{|l|}{ Raw dried meat } \\
\hline Yes & 122 & 46 & 37.7 & \multirow[t]{2}{*}{0.14} \\
\hline No & 86 & 24 & 27.9 & \\
\hline \multicolumn{5}{|l|}{ Floor at home } \\
\hline Ceramic or wood & 6 & 3 & 50 & \multirow[t]{3}{*}{0.19} \\
\hline Concrete & 102 & 28 & 27.5 & \\
\hline Soil & 106 & 40 & 37.7 & \\
\hline
\end{tabular}

*Subjects with available data.

higher than the mean (23.8\%) seroprevalence of $T$. gondii infection reported in the general population in rural areas in Durango State [18]. In addition, the seroprevalence in Huicholes is higher than the $6.1 \%$ seroprevalence of $T$. gondii infection reported in urban general population in the capital Durango City [19]. With respect to other ethnic groups in the region, the seroprevalence found in Huicholes is comparable with the $30.3 \%$ seroprevalence of T. gondii infection reported in Mennonites [9] but is higher than the $22.4 \%$ seroprevalence reported in
Table 4 Multivariate analysis of selected characteristics of Huicholes and their association with $T$. gondii infection

\begin{tabular}{lccc}
\hline Characteristic & Odds ratio & $\mathbf{9 5 \%}$ confidence interval & $\boldsymbol{P}$ value \\
\hline $\begin{array}{l}\text { Age (years) } \\
\text { 30 or less }\end{array}$ & 1.00 & & \\
$31-50$ & 0.73 & $0.32-1.66$ & 0.45 \\
$\quad>50$ & 1.23 & $0.44-3.47$ & 0.68 \\
Educational level & & & \\
$\quad$ No education & 2.08 & $0.83-5.19$ & 0.11 \\
1-6 years & 1.92 & $0.68-5.38$ & 0.21 \\
$>$ 6 years & 1.00 & & \\
Contact with dogs & 2.11 & $0.93-4.78$ & 0.07 \\
Consumption of: & & & \\
$\quad$ Goat meat & 1.61 & $0.46-5.60$ & 0.45 \\
$\quad$ Turkey meat & 2.28 & $1.16-4.46$ & 0.01 \\
$\quad$ Pigeon meat & 1.35 & $0.51-3.55$ & 0.53 \\
$\quad$ Raw dried meat & 1.20 & $0.63-2.30$ & 0.56 \\
\hline
\end{tabular}

Tepehuanos [10]. Huicholes and Tepehuanos live in the same mountains (Sierra Madre Occidental), however, Huicholes live in more remote places deeper into the mountainous region than Tepehuanos. It is known that the seroprevalence of $T$. gondii infection varies depending on the climate conditions in the communities, i.e., a low seroprevalence in dry and hot climate [14], and high seroprevalence in humid regions [12]. Huicholes communities are located in a lower region on the mountains with warmer and more humid climate than the one of the Tepehuanos settlements. However, difference in the seroprevalences among Huicholes and Tepehuanos should be interpreted with care because of an age limitation of the comparison: the mean age in Tepehuanos (31.03 \pm 16.71 years old) was lower than the one (37.98 \pm 15.80 years old) in Huicholes.

Toxoplasma exposure has been linked to low socioeconomic status [20,21], and such characteristics might have contributed to the increased seroprevalence of $T$. gondii infection in Huicholes. The seroprevalence of T. gondii infection in Huicholes with low socioeconomic status (34.3\%) was higher than in those with medium socioeconomic status (15.4\%). However, such increase was not statistically significant because of the limited number $(n=12)$ of subjects with medium socioeconomic status in the comparison. In the present study women outnumber men. The higher number of women than men in the study may be due to a number of factors including refusal of some men to participate, and more migration and violent deaths in men than in women in the study region. However, the imbalance in sexes in this study is unlikely to affect the seroprevalence rate since seroprevalence of $T$. gondii infection has been found similar in men and in women of general populations in rural [18] and urban [19] Durango, Mexico. 
Multivariate analysis of the socio-demographic and behavioral characteristics of the Huicholes allowed us to identify that consumption of turkey meat was positively associated with $T$. gondii exposure in Huicholes. In a previous study in the general population in rural Durango, consumption of turkey meat was also associated with T. gondii exposure [18]. In addition, in a study in pregnant women in the urban capital Durango City, consumption of turkey meat was associated with $T$. gondii infection too [22]. Turkey meat is a potential source for infection with T. gondii [23]. Experimental T. gondii oocyst infections in turkeys have shown the parasite spreading over the whole organism as determined by polymerase chain reaction [24]. In a previous study in birds in Durango, no serological evidence of $T$. gondii infection in 16 turkeys (Meleagris gallopavo) was found [25]. However, the number of studied turkeys was too small to exclude T. gondii infections in turkeys in Durango. Turkey meat is frequently cooked in big pieces; therefore, it is likely that this meat remains undercooked in some deep areas.

Seroprevalence of $T$. gondii infection usually increases with age in our region $[18,19,26]$. In the present survey, seroprevalence tended to increase with age; however, such increase did not reach statistical significance $(P=$ 0.09 ). It is likely that the small sample size of the oldest Huicholes subgroup prevented us obtaining a statistically significant difference.

Remarkably, in the present study we found an association of $T$. gondii exposure with the presence of dizziness and memory impairment in Huicholes. This finding may indicate a causal association of infection with $T$. gondii and central nervous system illness in Huicholes. The association of $T$. gondii exposure with dizziness and memory impairment was also found in a recent study in migrant agricultural workers in Durango [21]. The association of memory impairment and T. gondii exposure was also assessed in other ethnic groups in Durango including Mennonites [9] and Tepehuanos [10]; however, no association was found. The association of dizziness and $T$. gondii exposure was not assessed in Mennonites [9] and Tepehuanos [10]. We are not aware of further reports on the association of dizziness with $T$. gondii infection. On the other hand, the association of memory impairment with $T$. gondii infection found in the present study agrees with previous reports $[27,28]$. In a previous study in gardeners in Durango City, T. gondii seropositivity was associated with memory impairment [27]. In a recent study in seniors in Germany, researchers found that $T$. gondii seropositivity was associated with a reduction of about 35\% in working memory, a lower performance in verbal memory, and a decreased quality of life [28]. A number of reports indicate that $T$. gondii infection may lead to neurological and behavioral changes. Experiments in adult mice have shown that infections with $T$. gondii cause neurological and behavioral abnormalities secondary to inflammation and loss of brain parenchyma [29]. In addition, chronic infections with $T$. gondii in mice can damage the spatial learning and memory capability [30]. The behavioral alterations associated with $T$. gondii infection in humans and animals were recently reviewed by Flegr [31] and Webster et al., [32]. Intriguingly, latent T. gondii infection was associated with improvements in cognitive control processes in young healthy humans [33]. However, this effect might perhaps not be found or even reversed in old age. Beste et al. [34] found that latent T. gondii infection leads to deficits in goal-directed behavior in otherwise healthy elderly individuals.

Anti-T. gondii IgM antibodies were present in a high number of anti-T. gondii IgG positive Huicholes. Such high frequency of IgM positive results was unexpected and should be interpreted with care since IgM ELISA kits have a high rate of false positive results [35]. Therefore, discrimination between recent and latent $T$. gondii infections is not accurately obtained by ELISA. Other methods such as IgG avidity [36,37] may aid in such discrimination.

The present study has some limitations, including the sampling method and the small sample size of elderly Huicholes. We were unable to perform random sampling because participation of Huicholes in the study depended to a large extent on the permission of the Huicholes leaders. Huicholes leaders asked their people to participate and only Huicholes who attended the invitation were sampled. A small number of elders attended the invitation.

\section{Conclusion}

Our results demonstrate serological evidence of $T$. gondii exposure in Huicholes and Toxoplasma may be impacting their health. This is the first report of $T$. gondii infection in Huicholes, and results should be useful for the optimal design of preventive measures against T. gondii infection.

\section{Competing interests}

The authors declare that they have no competing interest.

\section{Authors' contributions}

CAE conceived and designed the study protocol, participated in the coordination and management of the study, performed the laboratory tests and the data analysis and wrote the manuscript. SJPV, LOBS, FJIRA, OAGG and FCR obtained blood samples, submitted the questionnaires and performed the data analysis. JHT, IBG, OL, LFSA and ERS performed the data analysis, and wrote the manuscript. All authors read and approved the final version of the manuscript.

\section{Author details}

'Biomedical Research Laboratory, Faculty of Medicine and Nutrition, Juárez University of Durango State, Avenida Universidad S/N, 34000 Durango, Dgo, Mexico. ${ }^{2}$ Institute for Scientific Research "Dr. Roberto Rivera-Damm", Juárez University of Durango State, Avenida Universidad S/N, 34000 Durango, Mexico. ${ }^{3}$ Servicios de Salud de Durango, Cuauhtémoc 225 norte, 34000 Durango, Mexico. ${ }^{4}$ Facultad de Enfermería y Obstetricia, Juárez University of 
Durango State, Cuauhtémoc 223 norte, 34000 Durango, Mexico. ${ }^{5}$ Institute for Microbiology and Hygiene, Campus Benjamin Franklin, Charité Medical School, Hindenburgdamm 27, D-12203 Berlin, Germany. ${ }^{6}$ Present address: Roche Molecular Diagnostics, Pleasanton, CA, USA.

Received: 21 March 2014 Accepted: 26 June 2014 Published: 1 July 2014

\section{References}

1. Dubey JP: Toxoplasmosis of animals and humans. 2nd edition. Boca Raton, Florida: CRC Press; 2010.

2. Hill DE, Chirukandoth S, Dubey JP: Biology and epidemiology of Toxoplasma gondii in man and animals. Anim Health Res Rev 2005, 6:41-61.

3. Montoya JG, Liesenfeld O: Toxoplasmosis. Lancet 2004, 363:1965-1976.

4. Weiss LM, Dubey JP: Toxoplasmosis: A history of clinical observations. Int J Parasitol 2009, 39:895-901.

5. Munoz M, Liesenfeld O, Heimesaat MM: Immunology of Toxoplasma gondii. Immunol Rev 2011, 240:269-285.

6. Lilly EL, Wortham CD: High prevalence of Toxoplasma gondii oocyst shedding in stray and pet cats (Felis catus) in Virginia, United States. Parasit Vectors 2013, 6:266. doi:10.1186/1756-3305-6-266.

7. Alvarado-Esquivel C, Torres-Castorena A, Liesenfeld O, Estrada-Martínez S, Urbina-Álvarez JD: High seroprevalence of Toxoplasma gondii infection in a subset of Mexican patients with work accidents and low socioeconomic status. Parasit Vectors 2012, 5:13. doi:10.1186/1756-3305-5-13.

8. Walle F, Kebede N, Tsegaye A, Kassa T: Seroprevalence and risk factors for Toxoplasmosis in HIV infected and non-infected individuals in Bahir Dar, Northwest Ethiopia. Parasit Vectors 2013, 6:15. doi:10.1186/1756-3305-6-15.

9. Alvarado-Esquivel C, Rojas-Rivera A, Estrada-Martínez S, Sifuentes-Álvarez A, Liesenfeld O, García-López CR, Dubey JP: Seroepidemiology of Toxoplasma gondii infection in a Mennonite community in Durango State, Mexico. J Parasitol 2010, 96:941-945.

10. Alvarado-Esquivel C, Estrada-Martínez S, García-López CR, Rojas-Rivera A, Sifuentes-Álvarez A, Liesenfeld O: Seroepidemiology of Toxoplasma gondii infection in Tepehuanos in Durango, Mexico. Vector Borne Zoonotic Dis 2012, 12:138-142.

11. Meerburg BG, Kijlstra A: Changing climate-changing pathogens: Toxoplasma gondii in North-Western Europe. Parasitol Res 2009, 105:17-24. doi:10.1007/s00436-009-1447-4.

12. Julvez J, Magnaval JF, Meynard D, Perie C, Baixench MT: Seroepidemiology of toxoplasmosis in Niamey, Niger. Med Trop (Mars) 1996, 56:48-50,

13. Assmar M, Amirkhani A, Piazak N, Hovanesian A, Kooloobandi A, Etessami R: Toxoplasmosis in Iran. Results of a seroepidemiological study. Bull SoC Pathol Exot 1997, 90:19-21.

14. Markovich MP, Shohat T, Riklis L, Avni R, Yujelevski-Rozenblit D, Bassal $R$, Cohen D, Rorman E: Seroepidemiology of Toxoplasma gondii infection in the Israeli population. Epidemiol Infect 2014, 142:149-155. doi:10.1017/S0950268813000903.

15. Almería S, Calvete C, Pagés A, Gauss C, Dubey JP: Factors affecting the seroprevalence of Toxoplasma gondii infection in wild rabbits (Oryctolagus cuniculus) from Spain. Vet Parasitol 2004, 123:265-270

16. Alvarado-Esquivel C, Silva-Aguilar D, Villena I, Dubey JP: Seroprevalence of Toxoplasma gondii infection in dairy goats in Michoacán State, Mexico. J Parasitol 2013, 99:540-542. doi:10.1645/12-103.1.

17. Alvarado-Esquivel C, Romero-Salas D, García-Vázquez Z, Crivelli-Diaz M, Barrientos-Morales M, Lopez-de-Buen L, Dubey JP: Seroprevalence and correlates of Toxoplasma gondii infection in domestic pigs in Veracruz State, Mexico. Trop Anim Health Prod 2014, 46:705-709. doi:10.1007/s11250-014-0551-3.

18. Alvarado-Esquivel C, Cruz-Magallanes HM, Esquivel-Cruz R, Estrada-Martínez S, Rivas-González M, Liesenfeld O, Martínez-García SA, Ramírez E, Torres-Castorena A, Castañeda A, Dubey JP: Seroepidemiology of Toxoplasma gondii infection in human adults from three rural communities in Durango State, Mexico. J Parasitol 2008, 94:811-816.

19. Alvarado-Esquivel C, Estrada-Martínez S, Pizarro-Villalobos H, Arce-Quiñones M, Liesenfeld O, Dubey JP: Seroepidemiology of Toxoplasma gondii infection in general population in a northern Mexican city. J Parasitol 2011, 97:40-43.

20. Yahaya N: Review of toxoplasmosis in Malaysia. Southeast Asian J Trop Med Public Health 1991, 22:102-106.
21. Alvarado-Esquivel C, Campillo-Ruiz F, Liesenfeld O: Seroepidemiology of infection with Toxoplasma gondii in migrant agricultural workers living in poverty in Durango, Mexico. Parasit Vectors 2013, 6:113.

22. Alvarado-Esquivel C, Sifuentes-Alvarez A, Narro-Duarte SG, Estrada-Martínez S, Díaz-García JH, Liesenfeld O, Martínez-García SA, Canales-Molina A: Seroepidemiology of Toxoplasma gondii infection in pregnant women in a public hospital in northern Mexico. BMC Infect Dis 2006, 6:113.

23. Koethe M, Pott S, Ludewig M, Bangoura B, Zöller B, Daugschies A, Tenter AM, Spekker K, Bittame A, Mercier C, Fehlhaber K, Straubinger RK: Prevalence of specific lgG-antibodies against Toxoplasma gondii in domestic turkeys determined by kinetic ELISA based on recombinant GRA7 and GRA8. Vet Parasitol 2011, 180:179-190.

24. Bangoura B, Zöller B, Koethe M, Ludewig M, Pott S, Fehlhaber K, Straubinger RK, Daugschies A: Experimental Toxoplasma gondii oocyst infections in turkeys (Meleagris gallopavo). Vet Parasitol 2013, 196:272-277.

25. Alvarado-Esquivel C, Rajendran C, Ferreira LR, Kwok OC, Choudhary S, Alvarado-Esquivel D, Rodríguez-Peña S, Villena I, Dubey JP: Prevalence of Toxoplasma gondii infection in wild birds in Durango, Mexico. $J$ Parasitol 2011, 97:809-812.

26. Alvarado-Esquivel C, Liesenfeld O, Burciaga-López BD, Ramos-Nevárez A, Estrada-Martínez S, Cerrillo-Soto SM, Carrete-Ramírez FA, López-Centeno Mde L, Ruiz-Martínez MM: Seroepidemiology of Toxoplasma gondii infection in elderly people in a northern Mexican city. Vector Borne Zoonotic Dis 2012, 12:568-574. doi:10.1089/vbz.2011.0875.

27. Alvarado-Esquivel C, Liesenfeld O, Márquez-Conde JA, Estrada-Martínez S, Dubey JP: Seroepidemiology of infection with Toxoplasma gondii in workers occupationally exposed to water, sewage, and soil in Durango, Mexico. J Parasitol 2010, 96:847-850.

28. Gajewski PD, Falkenstein M, Hengstler JG, Golka K: Toxoplasma gondii impairs memory in infected seniors. Brain Behav Immun 2014, 36:193-199.

29. Hermes G, Ajioka JW, Kelly KA, Mui E, Roberts F, Kasza K, Mayr T, Kirisits MJ, Wollmann R, Ferguson DJ, Roberts CW, Hwang JH, Trendler T, Kennan RP, Suzuki Y, Reardon C, Hickey WF, Chen L, McLeod R: Neurological and behavioral abnormalities, ventricular dilatation, altered cellular functions, inflammation, and neuronal injury in brains of mice due to common, persistent, parasitic infection. J Neuroinflammation 2008, 5:48.

30. Wang HL, Bao AY, Wang GH, Jiang MS, Liu ZC, Dong HF, Guo Y: Effect of chronic Toxoplasma infection on the spatial learning and memory capability in mice. Zhongguo Ji Sheng Chong Xue Yu Ji Sheng Chong Bing Za Zhi 2006, 24:114-118.

31. Flegr J: Influence of latent Toxoplasma infection on human personality, physiology and morphology: pros and cons of the Toxoplasma-human model in studying the manipulation hypothesis. J Exp Biol 2013, 216:127-133. doi:10.1242/jeb.073635.

32. Webster JP, Kaushik M, Bristow GC, McConkey GA: Toxoplasma gondii infection, from predation to schizophrenia: can animal behaviour help us understand human behaviour? J Exp Biol 2013, 216:99-112. doi:10.1242/jeb.074716.

33. Stock AK, Heintschel von Heinegg E, Köhling HL, Beste C: Latent Toxoplasma gondii infection leads to improved action control. Brain Behav Immun 2014, 37:103-108. doi:10.1016/j.bbi.2013.11.004.

34. Beste C, Getzmann S, Gajewski PD, Golka K, Falkenstein M: Latent Toxoplasma gondii infection leads to deficits in goal-directed behavior in healthy elderly. Neurobiol Aging 2014, 35:1037-1044. doi:10.1016/j. neurobiolaging.2013.11.012

35. Liesenfeld O, Press C, Montoya JG, Gill R, Isaac-Renton JL, Hedman K, Remington JS: False-positive results in immunoglobulin M (IgM) Toxoplasma antibody tests and importance of confirmatory testing: the Platelia Toxo IgM test. J Clin Microbiol 1997, 35:174-178.

36. Alvarado-Esquivel C, Sethi S, Janitschke K, Hahn H, Liesenfeld O: Comparison of two commercially available avidity tests for Toxoplasma-specific $\operatorname{lgG}$ antibodies. Arch Med Res 2002, 33:520-523.

37. Alvarado-Esquivel C, Niewiadomski A, Schweickert B, Liesenfeld O: Antiparasitic treatment suppresses production and avidity of Toxoplasma gondii-specific antibodies in a murine model of acute infection. Eur J Microbiol Immunol (Bp) 2011, 1:249-255. doi:10.1556/EuJMI.1.2011.3.9.

doi:10.1186/1756-3305-7-301

Cite this article as: Alvarado-Esquivel et al: Seroprevalence of Toxoplasma gondii infection and associated risk factors in Huicholes in Mexico. Parasites \& Vectors 2014 7:301. 